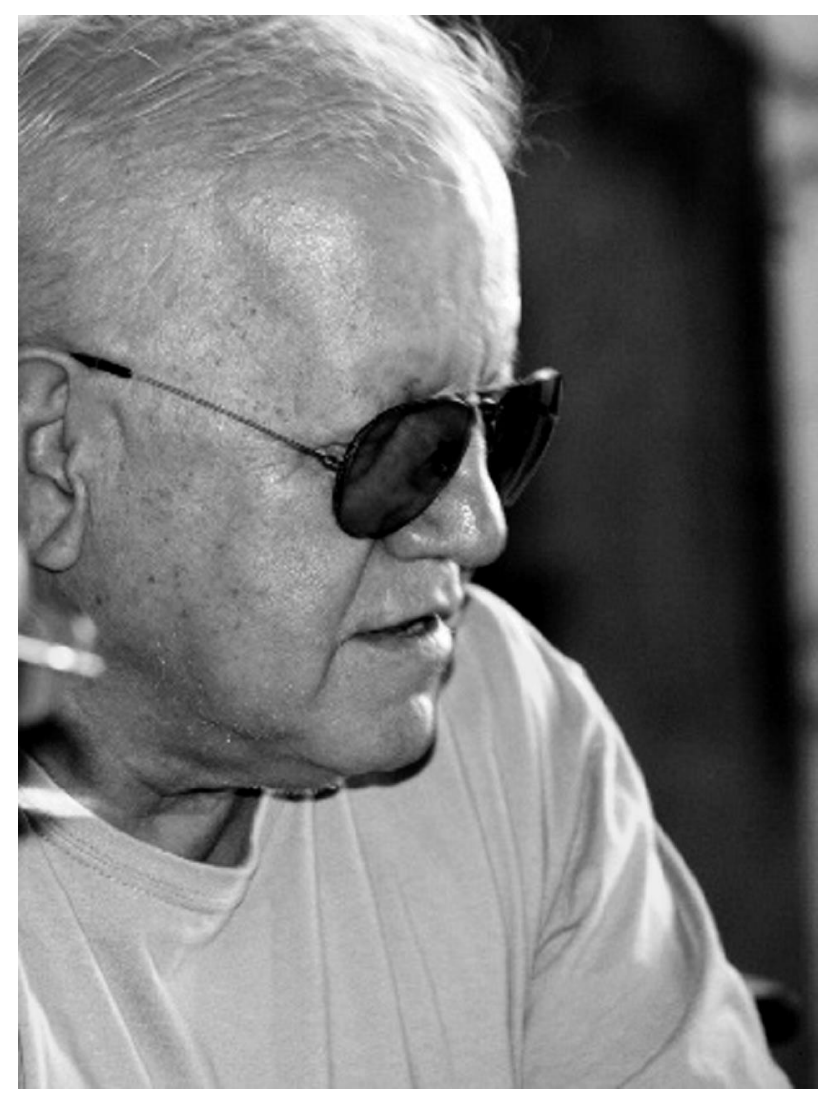

Foto: Rubens Rangel

\title{
Entrevista com Ronald Claver: um breve passeio pela literatura e cinema
}

\section{Ronald Claver \\ Por Jane Teixeira Dias e Maria José de Castro Alves}

Jane Teixeira Dias é licenciada em Letras (Lingua Portuguesa e Língua Espanhola) pela FALE/UFMG, Especializanda em Língua Portuguesa: Ensino de Leitura e Produção de Textos pela FALE/UFMG e Coordenadora do Setor de Capacitação de Educadores do Programa de Ensino Pesquisa e Extensão A tela e o texto FALE/UFMG.

Maria José de Castro Alves é licenciada em Letras (Língua Portuguesa e Literatura) pela Newton Paiva, Especializanda em Língua Portuguesa: Ensino de Leitura e Produção de Textos pela FALE/UFMG e Coordenadora do Setor Linha Editorial Tela e Texto do Programa de Ensino Pesquisa e Extensão A tela e o texto FALE/UFMG. 
"A poesia reside no mundo... A poesia, assim como o pão e o salário, deve fazer parte de nosso cotidiano... A condição única para o ato criador é a liberdade. Escrever é refletir. É um processo. Uma caminhada. Uma longa caminhada sem porto de chegada..."

Assim encontramos Ronald Claver, nosso entrevistado: mineiro, poeta, atleticano, devoto de São Francisco de Assis, iluminado pela lua apesar da sua condição de estrela, mobilizado formador de leitores. Autor de mais de duas dezenas de publicações reconhecidamente por um público diversificado, é parceiro da cultura, da boa literatura, da vida e da arte.

\section{Jane e Maria José - O cinema é cenário tanto em $A$ última sessão de cinema quanto em Os bigodes do Tio Sam e No escurinho do cinema, livro que, em seu site, você menciona ter reescrito no último final de ano. O que representa o cinema para o autor desses dois livros?}

Ronald Claver - Ainda peguei os cinemas de bairros de Belo Horizonte. São José (Calafate, Gameleira), Floresta (Floresta), São Carlos (Padre Eustáquio) etc. O cinema, assim como a missa, era o ponto de encontro dos namorados. Era ali que as coisas de amor começavam e aconteciam. E havia também os seriados (a novela de hoje), só que com muito mais ação e mistério. Seriado do Flash Gordon encantava a meninada e aos marmanjos. Passávamos a semana pensando como o Flash iria salvar Dale das mãos do Dr. Zarkov. O Indiana Jones retoma a ação e as aventuras dos seriados das matinês daquele tempo. E havia os filmes proibidos para menores de 18 anos. A Brigitte era a nossa musa e companheira de nossas safadezas e sonhos. Os faroestes eram o ponto máximo, assim como as chanchadas. No tempo das diligências, Shane (Os brutos também amam), Matar ou Morrer, Duelo de Titãs. Era tudo mágico e inocente. Havia também os álbuns de figurinhas com as estrelas de Hollywood. O cinema fazia parte de nossas vidas.

A última sessão de cinemalEditora FTD - $1^{\circ}$ prêmio Nestlé de Literatura Brasileira - SP) conta a história de uma turma de adolescentes que tem o cinema São José como referência. O São José era o ponto do encontro, era onde a turma se esbaldava e sonhava com o impossível. Chega a TV e sepulta o São José, a rua, a lua. As casas se verticalizam e o namorinho de portão tão casto e gostoso perde o seu lugar.

No escurinho do cinema (ainda sem editora) é uma sátira à política do governo. Há o Cine Abilene onde passa o seriado Saloon Brazil. O cinema acontece nas telas e nas ruas. As possíveis ficantes (não mais namoradas) têm nome das atrizes de Hollywood (BB, MM, DD, pela ordem Brigitte Bastos, Marylin Mendes, Dóris Dias, etc). As ruas e avenidas não ficam atrás: 
R. John Wayne (grande e mal acabada), praça E o Vento Levou etc. E há o duelo final entre João, o cucaracha (que traz no coldre uma dose de cachaça, torresmo e chouriçol versus sam, o abutre que carrega nos coldres chicletes Adams. Li quase toda a bibliografia sobre o faroeste americano e li algumas centenas de livrinho. Num deles, tomei conhecimento da visita do Oscar Wilde ao oeste americano. Começou uma conferência. O saloon encheu, mas como era um papo sem fim, os pistoleiros abandonaram as palavras do romancista e caíram nos braços das coristas, no carteado e no uísque. É uma história bonita que ficou nas retinas, na poeira das matinês, nos possíveis beijos, no pó de mico e nos jornais que antecediam ao filme. Tudo mágico e nostálgico.

\section{Como você vê a inserção da literatura brasileira no cinema?}

O cinema sempre utilizou a obra literária como roteiro para suas realizações. O primeiro grande prêmio do cinema brasileiro foi uma adaptação da peça de Dias Gomes, o pagador de promessas. Quem não se lembra de Vidas secas? Meu pé de laranja lima? Recentemente, mas não muito, Dona Flor e seus dois maridos, Gabriela, 0 Quatrilho. Cidade de Deus e recentemente Meu nome não é Johnny, Tropa de Elite. Dom, Os sete gatinhos, São Bernardo etc. Os cineastas perceberam que filmes baseados em obras literárias já nascem com sucesso. O público quer conferir a leitura do cinema. Embora saibamos que são linguagens diferentes. A literatura é um meio quente segundo McLuhan, já o cinema é um meio frio. A literatura aguça a imaginação. Cada um cria o seu personagem de acordo com a sua leitura. A minha Capitu será sempre minha. Se aparecer na tela, deixa de ser minha e será de todo mundo. Depois que Sônia Braga fez Gabriela, a gente não consegue dissociar a personagem da atriz.

Olavo Romano refere-se a Ronald Claver como "um poeta em qualquer lugar". Conhecê-lo é tomar conhecimento dessa verdade, é descobrir que a poesia pode estar no Bar do João, no Poesia com cachaça, no Mineirão, na hora do almoço com os alunos do COLTEC. Conte-nos sobre a experiência de viver a poesia em espaços inusitados. 


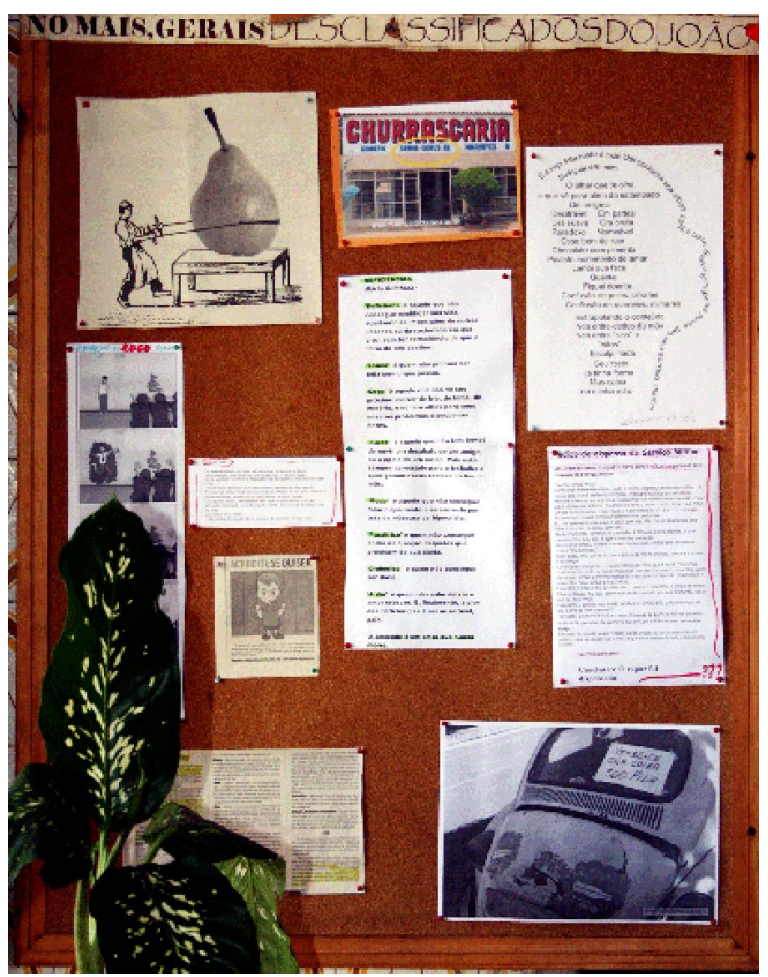

A poesia está no Bar do João porque tenho lá tem um mural que é mudado semanalmente e entre os recortes há espaço para a poesia. A poesia reside no mundo. A propaganda é pura poesia. Ela usa e abusa de seus efeitos sonoros. A poesia não pode ficar confinada em bibliotecas e salas de aulas. Ela, a poesia, gosta de alardear a sua prosa, gosta de grandes espaços, vozes, gente. Sempre gostei de poesia falada. Por isso reunia os alunos nos gramados do COLTEC para ler poesia em voz alta. É função nossa, amantes de poesia e em estado de poesia, propagá-la através dos dizeres em camisetas, recitais em bares e jardins. A poesia, assim como o pão e o salário, deve fazer parte de nosso cotidiano. A poesia não escolhe lugar para comparecer. Ela está aqui, ali, alhures. Já disse em uma das minhas falas que a poesia está na plumagem dos mares, no vôo das cachoeiras, na pele das tempestades, no barulho do silêncio, na velo acrobacia dos peixes, no verde sol e no ver do olho que tudo vê e não vê. A poesia? É só abrir os olhos e ver. 


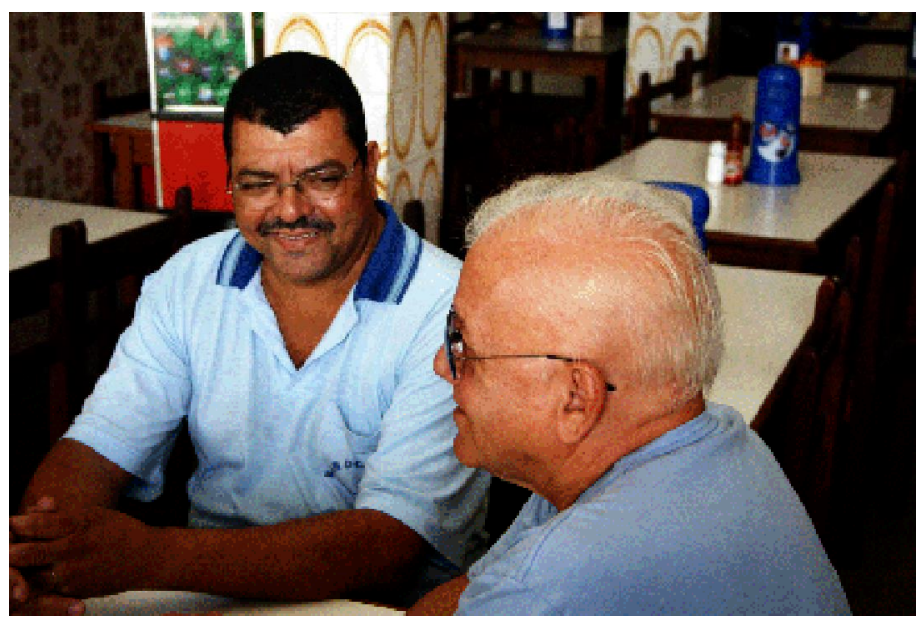

\begin{abstract}
A sua relação com a escrita é de muita intimidade. $\mathbf{E}$ quando sugere a escrita para o outro, também 0 faz como se esse outro pudesse apropriar-se dela com facilidade. Crê realmente que a escrita é para todos, que basta querer e esforçar-se?
\end{abstract}

Não faço mágicas, nem tenho o condão da fada escrivinhadora. Apresento processos. Na contracapa do livro Escrever sem doer falo que escrever é um ato de amor, de liberdade, de solidão. A condição única para o ato criador é a liberdade. Escrever é refletir. É um processo. Uma caminhada. Uma longa caminhada sem porto de chegada. É uma tentativa. O importante é o processo: o escrever e o riscar, o escrever e o mudar, o escrever e o tentar. O escrever e o arriscar de tornar o branco impuro, mas sem doer. Ninguém escreve nada do nada. Crio possibilidades para que a escrita aconteça. Todo mundo pode e deve escrever. Deve-se criar o hábito. A repetição da atividade é um aprendizado. Aprendemos a organizar o texto. Aprendemos, com o tempo, o tempo do texto. É importante que se escreva cotidianamente. O tempo todo se possível para a mão ficar boa. Criatividade não é dom, é aprendizado. Aprende-se criar, criando, aprende-se escrever, escrevendo. Neste meio tempo entra o ato de ler. Precisamos ler com criatividade. Ler - não lido. Pescar no rio (escrita) do outro a ponte (o peixe) para a nossa escrita. Para tentar o limbo, o talento ajuda. 